\title{
Pedal power measurement as a diagnostic tool for functional vascular problems
}

Citation for published version (APA):

Kleinloog, J. P. D., van Hooff, M., Savelberg, H. H. C. M., Meijer, E. J., \& Schep, G. (2019). Pedal power measurement as a diagnostic tool for functional vascular problems. Clinical Biomechanics, 61, 211-216. https://doi.org/10.1016/j.clinbiomech.2018.12.020

Document status and date:

Published: 01/01/2019

DOI:

10.1016/j.clinbiomech.2018.12.020

Document Version:

Publisher's PDF, also known as Version of record

Document license:

Taverne

Please check the document version of this publication:

- A submitted manuscript is the version of the article upon submission and before peer-review. There can be important differences between the submitted version and the official published version of record.

People interested in the research are advised to contact the author for the final version of the publication, or visit the DOI to the publisher's website.

- The final author version and the galley proof are versions of the publication after peer review.

- The final published version features the final layout of the paper including the volume, issue and page numbers.

Link to publication

\footnotetext{
General rights rights.

- You may freely distribute the URL identifying the publication in the public portal. please follow below link for the End User Agreement:

www.umlib.nl/taverne-license

Take down policy

If you believe that this document breaches copyright please contact us at:

repository@maastrichtuniversity.nl

providing details and we will investigate your claim.
}

Copyright and moral rights for the publications made accessible in the public portal are retained by the authors and/or other copyright owners and it is a condition of accessing publications that users recognise and abide by the legal requirements associated with these

- Users may download and print one copy of any publication from the public portal for the purpose of private study or research.

- You may not further distribute the material or use it for any profit-making activity or commercial gain

If the publication is distributed under the terms of Article $25 \mathrm{fa}$ of the Dutch Copyright Act, indicated by the "Taverne" license above, 


\title{
Pedal power measurement as a diagnostic tool for functional vascular problems
}

\author{
Jordi P.D. Kleinloog ${ }^{\mathrm{a}, \mathrm{b}, *}$, Martijn van Hooff ${ }^{\mathrm{a}, \mathrm{b}}$, Hans H.C.M. Savelberg ${ }^{\mathrm{a}}$, Eduard J. Meijer ${ }^{\mathrm{c}}$, \\ Goof Schep ${ }^{\mathrm{b}}$ \\ ${ }^{a}$ Maastricht University, NUTRIM, School for Nutrition and Translation Research Maastricht, Department of Nutritional and Human Movement Sciences, Universiteitssingel \\ 50, 6229 ER Maastricht, the Netherlands \\ ${ }^{\mathrm{b}}$ Máxima Medical Centre, Department of Sports and Exercise, De Run 4600, 5500 MB Veldhoven, the Netherlands \\ ${ }^{\mathrm{c}}$ Máxima Medical Centre, Department of Clinical Physics, De Run 4600, $5500 \mathrm{MB}$ Veldhoven, the Netherlands
}

\section{A R T I C L E I N F O}

\section{Keywords:}

Flow limitations

Iliac arteries

Ankle-brachial index

Endofibrosis

Exercise testing

\begin{abstract}
A B S T R A C T
Background: Cyclists with flow limitations in the iliac arteries complain of pain and loss of power. To investigate whether pedal power measurement has added value in diagnosing the underlying cause of flow limitations in the iliac arteries, we explored the sensitivity and specificity of various pedal power measurement variables. Moreover, it was assessed what the added value of pedal power measurement is compared to diagnosis based on the conventional ankle-brachial blood pressure index.

Methods: 25 healthy participants and 45 patients with unilateral arterial flow limitations were recruited. Participants received Echo-Doppler examination to determine the condition of the iliac arteries. Subsequently, participants performed a maximal cycle ergometer test. During the cycling test the exerted left and right pedal power was measured. From these measurements several variables were derived to diagnose arterial flow limitations. A receiver operating characteristics curve based on a predicted cross-validated model was used to select the variable with the highest predictive value and its cut-off value.

Findings: The mean power difference between both legs relative to the exerted power at $95 \%$ of the maximal power showed the best predictive value with a sensitivity of 0.76 and a specificity of 0.88 . Combining the pedal power measurement and ankle-brachial blood pressure index resulted in a sensitivity of 0.91 and a specificity of 0.88 .

Interpretation: Pedal power measurement improves sensitivity of diagnosis of iliac artery flow limitations, without increasing the burden of clinical investigation to the patients.
\end{abstract}

\section{Introduction}

Up to $20 \%$ of professional cyclists develop a sports-related flowlimitation in the iliac arteries (Schep et al., 2002c). Typical symptoms are exercise-induced leg-pain and loss of power at near-maximal exercise; the pain disappears within a few minutes after ceasing exercise (INSITE-Collaborators, 2016). It has been documented that not atherosclerosis but endofibrosis (thickening of the vessel intima), kinking of the iliac arteries or a combination or both underlie such flow limitations (Chevalier et al., 1986; Feugier and Chevalier, 2004; Schep et al., 2002a). Especially at an early stage, endofibrosis and iliac kinking are often not recognised, since current diagnostic tests lack sensitivity. It is of clinical importance to detect these vascular problems at an early stage, since at early stages conservative treatment or less invasive surgery may be sufficient.

Iliac artery kinking is suggested to stimulate endofibrosis; the latter may lead to arterial stenosis (Smith et al., 2008). Due to higher peak systolic velocities the hemodynamic stress in the vessel is increased, this may lead to intravascular damage resulting in endofibrosis (Schep et al., 2001a). A factor associated with the development of the iliac artery deformity is hip hyperflexion. To achieve an aerodynamic position, hyperflexion occurs frequently in sports like cycling and ice speed skating (Peach et al., 2012). The iliac artery runs in front of the hip joint and during hip flexion its length becomes redundant. This is solved by either elastic recoil or by an increase of tortuosity (bending or kinking of the vessel). Especially, if there is kinking, this repetitive deformation

\footnotetext{
* Corresponding author at: Maastricht University, Department of Nutrition and Movement Sciences, PO Box 616, 6200 MD Maastricht, the Netherlands.

E-mail addresses: j.kleinloog@maastrichtuniversity.nl (J.P.D. Kleinloog), martijn.vanhooff@maastrichtuniversity.nl, m.vanhooff@mmc.nl (M. van Hooff), hans.savelberg@maastrichtuniversity.nl (H.H.C.M. Savelberg), e.meijer@mmc.nl (E.J. Meijer), g.schep@mmc.nl (G. Schep).
} 
of the iliac arteries may stimulate endofibrotic changes (Bender et al., 2004). In some cases, the artery has been lengthened; this elongation of the artery makes the vessel more tortuous and increases the likelihood of kinking during hip flexion (Schep et al., 2002b).

To diagnose the iliac artery flow limitation a combination of tools is available, such as patient's history, physical examination, ultrasound examination, Ankle Brachial Index (ABI) of blood pressure after ceasing a maximal exercise on a cycling ergometer and Magnetic Resonance Angiography (MRA) (Bender et al., 2004). The best single test is ABI, assessed immediately following a maximal exercise cycling test. This test has a sensitivity of $73 \%$ for unilateral patients, while for bilateral patients the sensitivity is only 43\% (Abraham et al., 2001; Schep et al., 2002c). Consequently, early diagnosis of arterial kinking is difficult (Schep et al., 2001b).

A major complaint of cyclists with flow limitations is of loss of power in the affected leg. Therefore, pedal power measurement (PPM) may provide additional diagnostic value. It is assumed that healthy participants distribute the power equally between both legs independent of the total power generated. For patients with unilateral arterial flow limitations, it is expected that the power generated by the affected leg will not increase proportional at exercise intensities that demand more blood flow than can be supplied by the affected arteries. The healthy leg might compensate and give extra power. Therefore, variables that quantify the power difference between both legs at different intensities may provide added diagnostic value.

The purpose of this study was to investigate whether PPM is a useful method to diagnose patients with unilateral flow limitations. Therefore, we explored which PPM-variable is the most sensitive and specific for diagnosis of iliac flow limitations. Finally, the added diagnostic value of the best PPM-variable to ABI measurement has been assessed.

\section{Methods}

\subsection{Participants}

25 healthy and 45 patients ( 34 males and 11 females) participated in measurements to explore which variable was the most sensitive and specific indicator of iliac flow limitations and how much this variable added to the diagnostic value.

The following inclusion criteria were used: generally healthy; aged 18-65 years, trained cyclists for $>5$ years and on average $>5 \mathrm{~h}$ a week. Participants were excluded if they were suffering from pulmonary or cardiovascular disease or from a (neuro-) musculoskeletal problem that interacted with cycling. The local Medical Ethics Committee of Máxima Medical Centre, Veldhoven, The Netherlands approved the study. The study was conducted in accordance with the declaration of Helsinki.

\subsection{Vascular diagnosis}

Patients were recruited from a cohort of 372 patients that were examined with complaints suspect for iliac artery flow limitations in the period from January 30th 2013 till May 10th 2017 with flow limitations in the iliac artery. The diagnostic work-up in these patients consisted of patient history, physical examination and a standardised maximal exercise test and echo Doppler examination as described in more detail previously (Schep et al., 2001a; Schep et al., 2002c).

For our study only patients with definite documented flow limitation in the iliac arteries on echo-Doppler in one leg and no abnormality in the other leg were selected (Schep et al., 2001a; Schep et al., 2002c). Also patients with concomitating serious other underlying causes for complaints e.g. lumbar disc herniation were to be excluded. From 372 patients that were examined 144 patients had other underlying causes for their complaints. Another 139 patients had bilateral complaints. Of the other 89 vascular patients with unilateral complaints we still found in 44 patients abnormalities in both legs on echo-Doppler (endofibrosis, kinking and/or increased peak systolic velocities following criteria described in (Schep et al., 2002a; Schep et al., 2002c)) which was reason for exclusion.

Healthy participants were recruited from local cycling associations and were also screened for flow limitations in the iliac artery with echo Doppler and excluded if abnormalities were present. All examinations were performed and scored by medical sports doctor G. Schep who is experienced on diagnosing arterial flow limitations in the iliac arteries (Schep et al., 2001a; Schep et al., 2002c).

\subsection{Maximal exercise test}

Each participant performed a provocative, maximal ramp cycle tests on an electromagnetically braked cycle ergometer (Excalibur, a model with Pedal Power measurement through strain gauges bonded on each crank (925909), Lode, Groningen, the Netherlands). Participants were clipped into pedals of their own preference. The ergometer constantly corrected the instantaneous load to the actual pedal frequency to ensure that the actual load matched the set ergometer load. To provoke leg complaints, the test was performed in competitive posture with the trunk in an almost horizontal position. All participants were instructed to maintain this position during the entire maximal exercise test.

The exercise protocol consisted of a warm-up period followed by an individualized, linear, maximal ramp protocol, which led to exhaustion in 8 to $12 \mathrm{~min}$ (O'Connor, 2013). The warm-up period had a duration of 4 min at a workload of $10 \%$ of the estimated maximal workload based on gender, mass, and training status. Because we wanted to offer a familiar cycling experience, participants were instructed to keep a constant pedal frequency of their preference as long as it was above $80 \mathrm{rpm}$. When participants were exhausted or reached a pedal frequency below $70 \mathrm{rpm}$ the test was terminated.

\subsection{Blood pressure measurements}

After ceasing the maximal exercise test, participants were instructed to immediately detach from the pedals and to place their feet on a resting platform, which was placed at the area of the pedals over the bike. Participants had to remain seated in a competitive posture, while five subsequent blood pressure measurements simultaneously on the arm (Critikon 1846-SX, Soma Technology, Highland park Dr. Bloomfield, USA) and ankles (Duo, Datascope Corp., Mahwah, USA) were performed (O'Connor, 2013; Schep et al., 2002a). The first successful simultaneous blood pressure measurement was used for ABI analysis. The systolic blood pressure in the ankle was corrected for the height difference with the arm $(1 \mathrm{~cm}$ height difference $=0.76 \mathrm{~mm} \mathrm{Hg}$ ). The ABI was calculated using the following formula:

ABI

$=\frac{\text { systolic ankle blood pressure affected leg }-(0.76 \times \text { height difference })}{\text { systolic brachial blood pressure }}$

As a cut-off value for diagnosing arterial flow limitations, ABI of 0.54 was used (Schep et al., 2002a).

\subsection{Pedal power measurements}

The ergometer had a built-in pedal power technology, the pedal power measurement was based on the distortion of strain gauges implemented inside the crank. The software provided by the manufacturer (Lode Ergometer Manager 10) translated the distortion of the strain gauges to the torque $(\tau(\mathrm{Nm})$ ) exerted on both pedals independently.

Based on the cadence (c), measured as revolutions per minute (rpm), angular speed was calculated $(\omega=2 \pi * \mathrm{c} / 60(\mathrm{rad} / \mathrm{s}))$. Subsequently, the power (P (W)) was calculated by multiplying angular speed and torque measured: $\mathrm{P}=\tau * \omega$. 


\subsection{Data analysis}

First, outliers (e.g. unwanted body movements such as standing) were detected using a Hampel filter. If the outlier exceeds three standard deviations from the median of itself and three neighbouring data points of the median value, it is replaced with the median (Pearson, 2002). Thereafter, the data was filtered using a moving average filter with a window of 11 data points.

The maximal power was determined when participants showed a $5 \%$ decrease of the median pedal frequency. The analyzed data ranged from the moment after the warm-up (0\%) period until maximal power was reached $(100 \%)$.

The power exerted by both legs together equals the ergometer load. In an ideal situation, in healthy individuals the power exerted by both legs would be almost equal. In patients with functional vascular problems, kinking, endofibrosis or a combination of both limits the blood supply in the affected leg. Consequently, especially at high effort the blood supply towards the affected leg is unable to meet the oxygen and substrate demands. Due to this it is expected that the muscles in the affected leg will be unable to produce the same power as those in the healthy leg (Joyner and Casey, 2015). As a result, it is to expect that the power difference between healthy and affected leg will increase with increasing load. Therefore, the power difference between both legs at $95 \%$ and $99 \%$ of the maximal (100\%) exerted power was selected to test the potential most discriminating variable (Fig. 1A). Additionally, we hypothesized that power differences between both legs at submaximal exercise intensities could be present, due to individual differences like a stronger preference leg. These differences should be visible in healthy persons throughout the complete test and in patients only at submaximal exercise intensities when there is still no discrepancy between blood supply and blood demand. In an additional analysis, the variable with the highest sensitivity and specificity at maximal intensity with the power difference at submaximal exercise intensity (25\%) was therefore corrected.

For each pedal cycle, the mean and the maximal power was calculated. To compensate for inter-cycle variability, the maximal and mean power were averaged over 10 pedal cycles. This resulted in the mean and maximal power difference between both legs averaged over 10 pedal cycles at $95 \%$ and $99 \%$ of the maximal generated power at the maximal exertion test. To compensate for inter-individual differences in maximal exerted power, the power difference between both legs for the maximally generated mean power was normalized. This was calculated using the following formula:

normalized power $=\frac{\mid \text { Power difference between both legs } \mid}{\text { Maximal generated power }} \times 100$

Variables were checked for normal distribution using a graphical method (histogram) and Shapiro-Wilk tests. For statistical significance, alpha was set at 0.05 . Anthropometrics from healthy participants and participants were tested for significant differences using an independent $t$-test. The mean and maximal pedal power exerted with the left and right leg for healthy participants and affected and unaffected leg for patients was tested for significant difference using a paired $t$-test. Receiver operating characteristic (ROC) curves were generated to determine the variable that performed best on predicting patients with arterial flow limitations. The ROC curves compare sensitivity versus specificity across a range of cut-off values for the ability to predict a dichotomous outcome (Florkowski, 2008). The sensitivity $\left(\frac{\Sigma \text { True Positive }}{\Sigma \text { Condition Positive }}\right)$ is defined as the proportion of positives that are correctly identified, while the specificity $\left(\frac{\Sigma \text { True Negative }}{\Sigma \text { Condition negative }}\right)$ is defined as the proportion of negatives that are correctly identified. Thereafter, the optimal cut-off point was determined using the Youden Index, which defines the maximum potential effectiveness of a biomarker (HajianTilaki, 2013). The Youden Index optimizes the biomarker's differentiating ability when equal weight is given to sensitivity and specificity. If for example, preference would be given to specificity, this would have a disadvantageous effect on the sensitivity. Using the $\mathrm{R}$ caret function a 10 -fold cross-validation with 100 repeats was performed to increase the precision of the sensitivity and specificity estimates while still maintaining a small bias, since the model is based and validated on the same participant group. The cross-validation model was trained using a generalised linear model. The used predictive modelling process is described in more detail by the authors of the $\mathrm{R}$ caret function (Kuhn and Johnson, 2013).

Finally, the diagnostic value of the ABI using the previously reported cut-off value of 0.54 was determined (Schep et al., 2002a). Also, the predictive and corresponding cut-off values were determined using the previously described cross-validation method. Additionally, the added value of PPM was determined by investigating the predictive value of a combination of the PPM and ABI. If the predicted population met either the PPM or the ABI criteria, they were classified as patient with flow limitations in the iliac arteries.

\section{Results}

\subsection{Participants}

Age, length, weight, BMI and distance cycled during lifetime did not significantly differ between the healthy participants and patients for the sensitivity and specificity analysis (Table 1 ). The maximal workload $\left(\mathrm{P}_{\max }\right)$, maximal workload per kilogram body weight $\left(\mathrm{P}_{\max } /\right.$ weight $)$ and $\mathrm{ABI}$ for the affected side as well as the non-affected side differed significantly between healthy participants and patients (Table 1). The patient group that was used for the sensitivity and specificity analysis had primarily vascular problems located in the external iliac artery (26 participants). Besides, unilateral vascular problems were predominant on the left side (33 participants) (Table 1). All data were normally distributed.

\subsection{Pedal power}

Typically, the pedal power generated by the left and the right leg increased linearly with ergometer load (Fig. 1A). In patients, the power increase of the affected leg declined above a specific ergometer load (Fig. 1A and B). Over one pedal cycle, the power generated by either the right or left leg showed a sinusoidal pattern (Fig. 1B).

\subsection{Diagnostic values}

There was no significant difference between the affected and unaffected leg at the mean and maximal power exerted at 95\% and $99 \%$ in healthy participants. In patients with arterial flow limitations the mean and maximal power exerted at $95 \%$ and $99 \%$ were significantly lower in the affected leg compared to the unaffected leg (Table 2).

The mean power difference between both legs at $95 \%$ of the maximal reached power (Fig. 2) had a sensitivity of 0.76 , the specificity was 0.88 using 5.10 as cut-off value. The mean power difference between both legs at $99 \%$ of the maximal power showed a sensitivity of 0.66 at a specificity of 0.92 using a cut-off value of 4.73 . The maximal power difference between both legs at $95 \%$ had a sensitivity of 0.60 with a specificity of 0.88 using a cut-off value of 17.22 . The maximal power difference between both legs at $99 \%$ showed a sensitivity of 0.71 and a specificity of 0.76 using a cut-off value of 19.27 . The sensitivity of the ratio of the mean power difference between both legs at $95 \%$ and $25 \%$ was 0.56 with a specificity of 0.80 , using a cut-off value of 0.40 .

\subsection{Comparison PPM and ABI}

For the healthy participants mean corrected ABI was 0.94 (SD 0.13), the mean corrected ABI for the affected leg in patients was 0.63 (SD 0.16 ). Using previously reported cut-off value of 0.54 , this resulted in a 

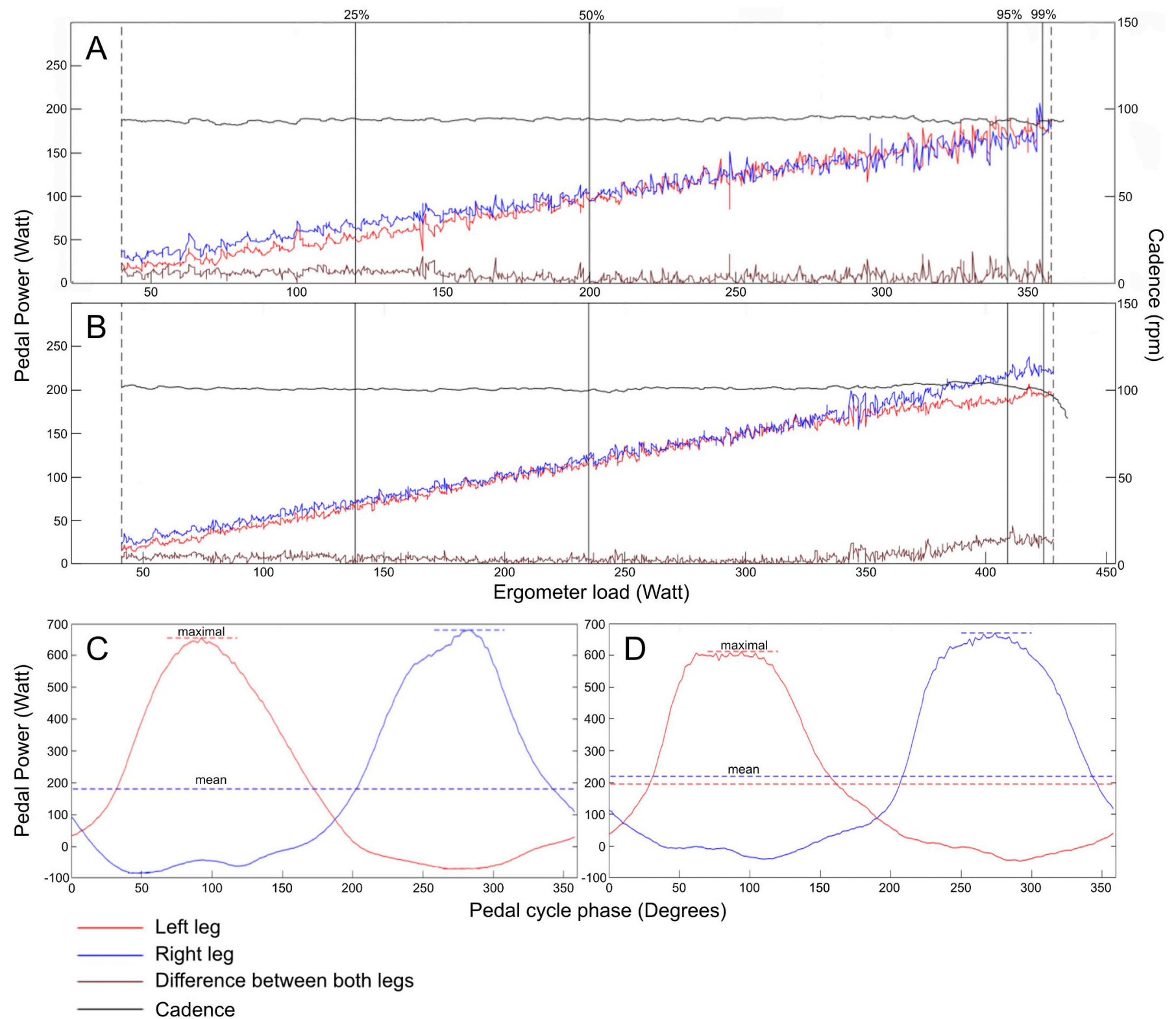

Fig. 1. Typical power pattern with increasing ergometer load of a healthy participant (A) and of a unilateral vascular patient (B). Typical power pattern over one pedalling cycle of a healthy participant (C) and of a unilateral vascular patient (D). Fig. A and B show the measured Pedal Power and the increasing power difference between both legs with increasing ergometer load for a unilateral vascular patient, while fore the healthy subject the power exerted by both legs is almost equal. The vertical dotted lines show the start ( $0 \%$ ) and the end (100\%) of the maximal cycling test; the solid vertical lines show $25 \%, 50 \%, 95 \%$ and $99 \%$ of the maximal cycling test. B) Shows the power measured during one pedal cycle for both legs independently. The horizontal dotted lines represent the mean and maximal variables for both legs as used for data analysis.

sensitivity of 0.76 and a specificity of 1 . Performing the ROC-curve analysis on the cross validated predicted model results in a sensitivity of 0.78 while maintain a specificity of 1 using a cut-off value of 0.67 . For further analysis we worked with a cut-off value of 0.54 , to make the results comparable with previous reports. The mean power difference between both legs at 95\% combined with the ABI using the current study population resulted in a sensitivity of 0.91 and a specificity of 0.88 .

\section{Discussion}

This study was designed to explore whether PPM had an added value for diagnosing iliac artery flow limitations and to explore which PPM-variable was most sensitive and specific, and to compare the predictive power of this variable to the conventional ABI-test. The variable with the best predictive value was the mean power difference relative to the exerted power at $95 \%$ of the maximal power (sensitivity 0.76 ; specificity 0.88 ) with a cut-off value of 5.10 .

Combining this PPM variable with ABI shows an increase in sensitivity from 0.76 to 0.91 , the specificity decreases from 1.00 to 0.88 . Meaning that an additional $13 \%$ patients with flow limitations were correctly identified, while approximately $7 \%$ healthy participants would have been wrongly identified as having flow limitations. Accordingly, both methods measure different effects of functional arterial flow limitations. Therefore, PPM can be effectively used complementary to $\mathrm{ABI}$ and to quantify both flow limitation and loss of power.

While determining the diagnostic values the power difference between both legs decreased at a maximal intensity (99\%), which may be due to fatigue of the healthy leg resulting in a power increase of the 
Table 1

Anthropometric measurements of the included participants for both the sensitivity and specificity study and the reliability analysis.

\begin{tabular}{|c|c|c|}
\hline & $\begin{array}{l}\text { Healthy participants } \\
(\mathrm{n}=25)\end{array}$ & Patients $(n=45)$ \\
\hline Age (years) & 33.6 (SD 12.9) & 39.9 (SD 14.3) \\
\hline Length $(\mathrm{cm})$ & $182(\mathrm{SD} 6)$ & $180(\mathrm{SD} 8)$ \\
\hline Weight (kg) & 71.9 (SD 6.5) & 76.4 (SD 20.6) \\
\hline BMI $\left(\mathrm{kg} / \mathrm{m}^{2}\right)$ & $21.7($ SD 1.6) & $23.4(\mathrm{SD} 5.4)$ \\
\hline Sport & 25 cyclists & $\begin{array}{l}32 \text { cyclists } \\
6 \text { ice skaters } \\
4 \text { triathletes } \\
2 \text { runners } \\
1 \text { rower }\end{array}$ \\
\hline Competitive level & $\begin{array}{l}0 \text { professional } \\
20 \text { national } \\
5 \text { recreational }\end{array}$ & $\begin{array}{l}6 \text { professional } \\
19 \text { competitive } \\
20 \text { recreational }\end{array}$ \\
\hline Cycled in lifetime $(\mathrm{km})$ & 186,915 (SD 155655) & 152,365 (SD 129296) \\
\hline $\operatorname{Pmax}(W)$ & $438($ SD 50) & $358(\mathrm{SD} 90)$ \\
\hline Pmax/weight (W/kg) & $6.12(\mathrm{SD} 0.74)$ & $4.93(\mathrm{SD} 1.58)$ \\
\hline ABI left/affected side ${ }^{a}$ & 0.76 (SD 0.13) & $0.41(\mathrm{SD} 0.17)$ \\
\hline $\begin{array}{l}\text { ABI right/non-affected } \\
\text { side }^{\mathrm{a}}\end{array}$ & 0.81 (SD 0.13) & $0.57(\mathrm{SD} \mathrm{12)}$ \\
\hline Side of vascular problem & None & $\begin{array}{l}33 \text { left } \\
12 \text { right } \\
0 \text { bilateral }\end{array}$ \\
\hline Type of vascular problem & - & $\begin{array}{l}8 \text { kinking } \\
18 \text { endofibrosis } \\
19 \text { both }\end{array}$ \\
\hline $\begin{array}{l}\text { Location of vascular } \\
\text { problem }\end{array}$ & - & $\begin{array}{l}26 \text { external iliac a. } \\
9 \text { common iliac a. } \\
10 \text { both }\end{array}$ \\
\hline
\end{tabular}

a For healthy participants left or right side. For unilateral vascular patients the ABI is reported as the affected and non-affected side. For bilateral vascular patients the ABI is reported as the most-affected and least-affected side.

Significant different from healthy participants $(\mathrm{P}<0.001)$.

affected leg. Besides, at near maximal exercise participants had the tendency to decrease their rpm faster than the ergometer can correct for. Since the ergometer load is dependent on cadence, this resulted in a decrease in the exerted power. Furthermore, the participants tended to compensate by adopting different cycling techniques and positions. The shift in power distribution between both legs in relation to the decrease in cadence at near maximal exercise may explain the highest diagnostic value of $95 \%$ instead of $99 \%$ of the maximal exerted power.

To correct for power differences present at submaximal intensities, the mean power difference at $95 \%$ relative to the power difference at submaximal exercise intensity (25\%) was used. This variable was proposed, because at low intensities there is still a balance between demand for blood flow and actual blood flow. Especially at the higher intensities we expect that the flow of blood is less than is required by the working muscle in the affected leg. Also, several individual patients showed an opposite power difference between both legs at submaximal intensities compared to maximal intensities. We believed that that correcting for this baseline might increase the sensitive and/or specificity value. However, this study showed that on group level this was not the case.

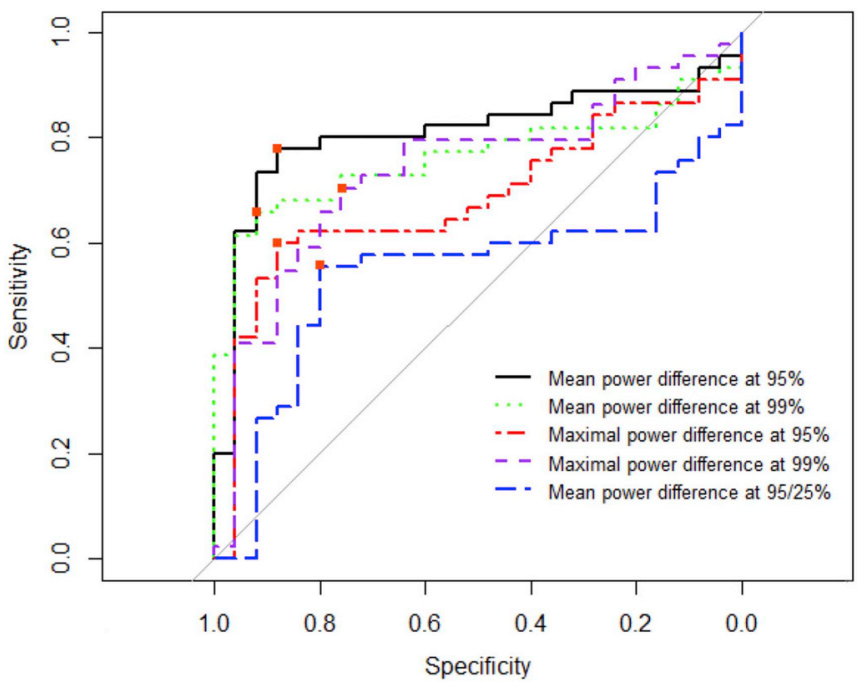

Fig. 2. Receiver operating characteristic (ROC)-curve of the mean and maximal power difference between both legs during the pedal revolution averaged over ten cycles relative to the exerted power at $95 \%$ and $99 \%$ of the maximal exercise test. Also, the ratio of the mean power difference between both legs at $95 \%$ between $25 \%$ of the maximal test is shown within the ROC-curve. The square dots on the lines correspond to the optimal cut-off point based on the Youden-method.

To our knowledge, this is the first study examining PPM as a diagnostic tool for arterial flow limitations. The idea of using PPM originates from the fact that the main complaint of cyclists with flow limitations consists of a loss of power in the affected leg with increasing exercise intensity. PPM is an easily available measurement tool on an ergometer and since a maximal cycling test is already being performed for determining $\mathrm{ABI}$ to diagnose arterial flow limitations no extra effort is necessary. Therefore, including this variable in the current diagnostic algorithm requires no additional discomfort for the patient, while adding diagnostic value. Also, PPM is currently increasingly applied during cycling practice and there are systems on the market that pretend to measure pedal power in both legs independently. Our study indicates that power differences at near maximal intensity may be an indicator for an underlying flow limitation.

Limitations to apply pedal power measurements in the diagnosis of flow limitations arise in patients with bilateral flow limitation and both sided complaints. However, also in these patients, information on pedal power may help to determine which leg is most affected and has the highest power deficit. In our experience, this is sometimes not the leg that the patient identifies, which underlines the clinical importance for objective measurement. Pedal power measurement may than help in guiding treatment since it gives more objective information on which leg is most affected and may benefit most from operation. Another limitation of this study is the generalisability to a more heterogeneous population, since the studied population did not suffer from other complaints except for arterial flow limitations. This would be an important next step in validating PPM as diagnostic tool. Additionally, to increase the precision of the prediction we used a cross-validation

Table 2

Pedal power exerted on the left and right side for healthy participants and on the affected and unaffected side for patient.

\begin{tabular}{|c|c|c|c|c|c|c|}
\hline & \multicolumn{3}{|c|}{ Healthy participants } & \multicolumn{3}{|l|}{ Patients } \\
\hline & Left & Right & P-value & Affected & Unaffected & P-value \\
\hline Mean power $95 \%(W)$ & 208 (SD 30) & 209 (SD 29) & 0.914 & $150(\mathrm{SD} 48)$ & 179 (SD 48) & $<0.001$ \\
\hline Mean power 99\% (W) & 215 (SD 28) & 215 (SD 30) & 0.951 & 156 (SD 47) & 185 (SD 46) & $<0.001$ \\
\hline Maximal power $95 \%(\mathrm{~W})$ & 816 (SD 126) & 810 (SD 12) & 0.730 & 618 (SD 141) & 694 (SD 134) & $<0.001$ \\
\hline Maximal power $99 \%(\mathrm{~W})$ & 816 (SD 126) & 819 (SD 12) & 0.889 & 623 (SD 137) & 708 (SD 125) & $<0.001$ \\
\hline
\end{tabular}


model which was the best option given the current data (Kuhn and Johnson, 2013). However, PPM to diagnose arterial flow limitations should also be validated on another different population.

This study focused on the power exerted over the whole testing range. Further research may focus on the reproducibility of the proposed pedal power variable. Besides, flow limitations in the iliac arteries may result in different muscle activation patterns during the pedal revolution based on the blood vessel anatomy. Therefore, information on pedal power pattern changes during the pedal cycled could provide additional diagnostic information (Hug and Dorel, 2009).

Additionally, pedal power measurement is increasingly used in the field, misbalance between the exerted power between legs combined with typical complaints could provide an early indication of flow limitations in the iliac arteries. The current study already provides a better understanding of the (pathologic) patterns that can be expected. Also, in patients treated for flow limitations power measurement may provide more objective data on the effectiveness of treatments and may guide rehabilitation/training to competitive level.

\section{Conclusion}

PPM is a useful additional tool for the current algorithm to diagnose flow limitations in the iliac arteries in athletes, without being an extra burden for the patient. The mean power difference between both legs relative to the power exerted at $95 \%$ of the maximal achieved power is the most discriminating variable with 5.10 as the cut-off value. Further research may optimize the application of PPM as a diagnostic tool.

\section{Conflict of interest}

The authors declare to have presented the results of this study clearly, honestly, and without fabrication, falsification, or inappropriate data manipulation. The authors have no conflict of interest to report.

\section{Acknowledgement}

We would like to thank data scientist Tim C.P. Kleinloog for his contributions on the R caret cross-validation model.

\section{Funding}

ZonMw projectnumber: 75020017.

\section{Author contribution}

Jordi Kleinloog: Conceptualization, Methodology, Software, Formal Analysis, Investigation, Writing - Original Draft, Visualization. Martijn van Hooff: Conceptualization, Methodology, Software,
Validation, Formal Analysis, Investigation, Resources, Writing - Review \& Editing, Visualization, Project Administration Hans Savelberg: Conceptualization, Methodology, Writing - Review \& Editing, Supervision. Eduard Meijer: Conceptualization, Methodology, Writing - Review \& Editing. Goof Schep: Conceptualization, Methodology, Investigation, Resources, Writing - Review \& Editing, Supervision, Project Administration.

\section{References}

Abraham, P., Bickert, S., Vielle, B., Chevalier, J.M., Saumet, J.L., 2001. Pressure measurements at rest and after heavy exercise to detect moderate arterial lesions in athletes. J. Vasc. Surg. 33, 721-727.

Bender, M.H., Schep, G., de Vries, W.R., Hoogeveen, A.R., Wijn, P.F., 2004. Sports-related flow limitations in the iliac arteries in endurance athletes: aetiology, diagnosis, treatment and future developments. Sports Med. (Auckland N.Z.) 34, 427-442.

Chevalier, J.M., Enon, B., Walder, J., Barral, X., Pillet, J., Megret, A., Lhoste, P., SaintAndre, J.P., Davinroy, M., 1986. Endofibrosis of the external iliac artery in bicycle racers: an unrecognized pathological state. Ann. Vasc. Surg. 1, 297-303.

Feugier, P., Chevalier, J.M., 2004. Endofibrosis of the iliac arteries: an underestimated problem. Acta Chir. Belg. 104, 635-640.

Florkowski, C.M., 2008. Sensitivity, specificity, receiver-operating characteristic (ROC) curves and likelihood ratios: communicating the performance of diagnostic tests. Clin. Biochem. Rev. 29 (Suppl. 1), S83-S87.

Hajian-Tilaki, K., 2013. Receiver operating characteristic (ROC) curve analysis for medical diagnostic test evaluation. Caspian J. Intern. Med. 4, 627-635.

Hug, F., Dorel, S., 2009. Electromyographic analysis of pedaling: a review. J. Electromyogr. Kinesiol. 19, 182-198.

INSITE-Collaborators, 2016. Diagnosis and management of iliac artery endofibrosis: results of a Delphi consensus study. Eur. J. Vasc. Endovasc. Surg. 52, 90-98.

Joyner, M.J., Casey, D.P., 2015. Regulation of increased blood flow (hyperemia) to muscles during exercise: a hierarchy of competing physiological needs. Physiol. Rev. 95, 549-601.

Kuhn, M., Johnson, K., 2013. Applied Predictive Modeling. Springer, New York.

O'Connor, F.G., 2013. ACSM's Sports Medicine: A Comprehensive Review. Wolters Kluwer Health/Lippincott Williams \& Wilkins, Philadelphia (etc.).

Peach, G., Schep, G., Palfreeman, R., Beard, J.D., Thompson, M.M., Hinchliffe, R.J., 2012. Endofibrosis and kinking of the iliac arteries in athletes: a systematic review. Eur. J. Vasc. Endovasc. Surg. 43, 208-217.

Pearson, R.K., 2002. Outliers in process modeling and identification. IEEE Trans. Control Syst. Technol. 10, 55-63.

Schep, G., Bender, M.H., Schmikli, S.L., Wijn, P.F., 2001a. Color Doppler used to detect kinking and intravascular lesions in the iliac arteries in endurance athletes with claudication. Eur. J. Ultrasound 14, 129-140.

Schep, G., Kaandorp, D.W., Bender, M.H., Weerdenburg, H., van Engeland, S., Wijn, P.F., 2001b. Magnetic resonance angiography used to detect kinking in the iliac arteries in endurance athletes with claudication. Physiol. Meas. 22, 475-487.

Schep, G., Bender, M.H., Schmikli, S.L., Mosterd, W.L., Hammacher, E.R., Scheltinga, M., Wijn, P.F., 2002a. Recognising vascular causes of leg complaints in endurance athletes. Part 2: the value of patient history, physical examination, cycling exercise test and echo-Doppler examination. Int. J. Sports Med. 23, 322-328.

Schep, G., Kaandorp, D.W., Bender, M.H., Van Engeland, S., Weerdenburg, H., Titulaer, B.M., Wijn, P.F., 2002b. Excessive length of iliac arteries in athletes with flow limitations measured by magnetic resonance angiography. Med. Sci. Sports Exerc. 34, 385-393.

Schep, G., Schmikli, S.L., Bender, M.H., Mosterd, W.L., Hammacher, E.R., Wijn, P.F., 2002c. Recognising vascular causes of leg complaints in endurance athletes. Part 1: validation of a decision algorithm. Int. J. Sports Med. 23, 313-321.

Smith, W.B., Olmsted, K.A., Zierler, R.E., 2008. Iliac artery endofibrosis in athletes: a case series. J. Vasc. Ultrasound 32, 193-199. 